Alma Mater Studiorum - Università di Bologna DEPARTMENT OF ECONOMICS

Fiscal Policy Announcements of Italian Governments and Spread Reaction during the Sovereign Debt Crisis

Matteo Falagiarda Wildmer Daniel Gregori

Quaderni - Working Paper DSE N961

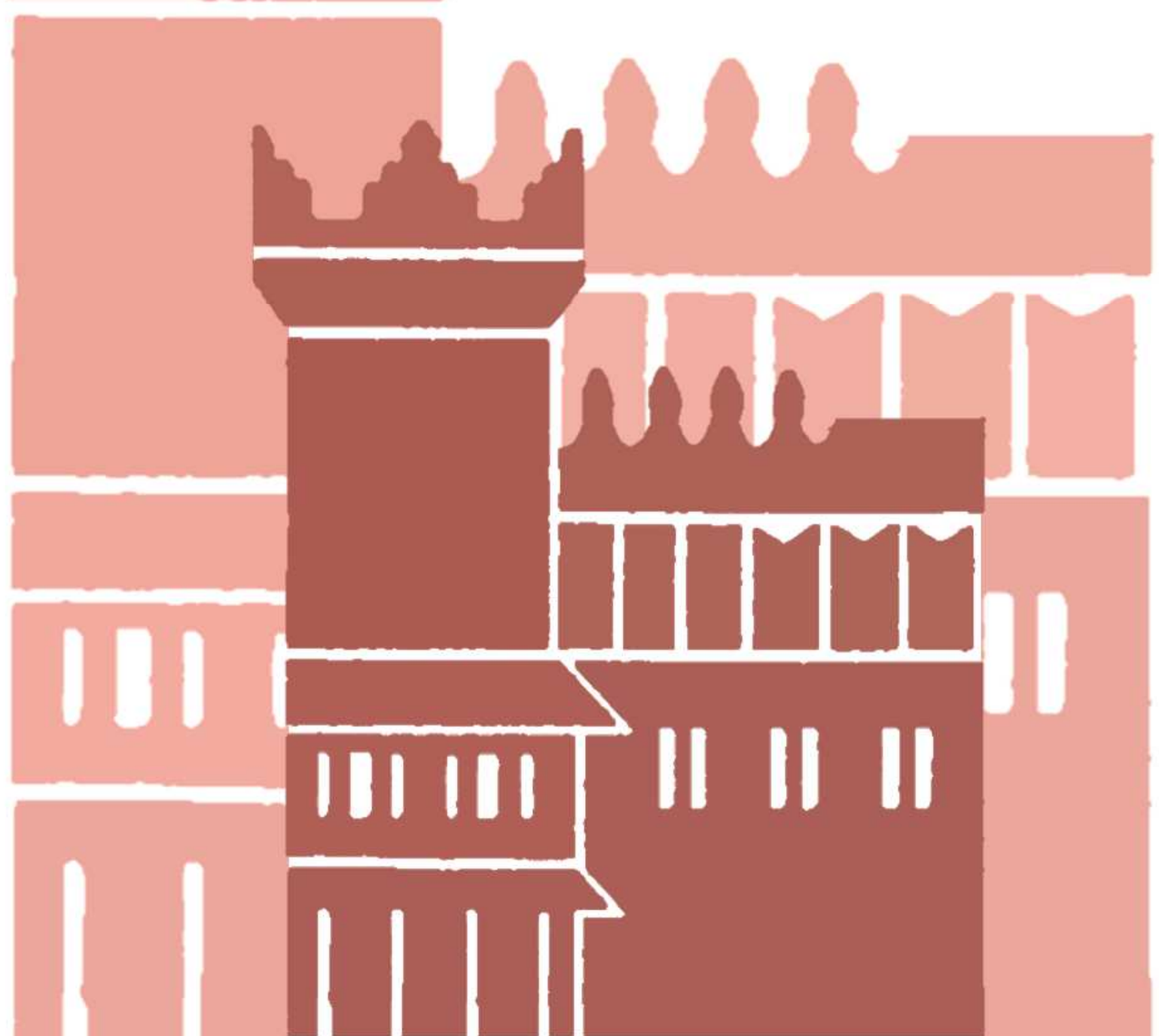




\title{
Fiscal Policy Announcements of Italian Governments and Spread Reaction during the Sovereign Debt Crisis
}

\author{
Matteo Falagiarda* Wildmer Daniel Gregori ${ }^{\dagger}$
}

September $2014^{\ddagger}$

\begin{abstract}
This paper attempts to evaluate the effects of fiscal policy announcements by the Italian government on the long-term sovereign bond spread of Italy relative to Germany. After collecting data on relevant fiscal policy announcements, we perform an econometric comparative analysis between the three cabinets that followed one another during the period 2009-2013. The results suggest that only fiscal policy announcements made by members of Monti's cabinet have been effective in influencing the Italian spread, revealing a remarkable credibility gap between Monti's technocratic administration and Berlusconi's and Letta's governments.
\end{abstract}

JEL codes: E43, E62, G01, G12

Keywords: Fiscal policy announcements, political communication, Italian government, sovereign debt crisis, interest rate spread, GARCH models

\footnotetext{
*Department of Economics, University of Bologna. E-mail: matteo.falagiarda2@unibo.it

${ }^{\dagger}$ Department of Economics, University of Bologna. E-mail: wildmer.gregori@unibo.it

‡We thank Massimo Bordignon and Paolo Manasse for valuable suggestions. Any errors remain our responsibility.
} 


\section{Introduction}

The recent economic crisis challenged the ability of national governments to guarantee economic stability and the sustainability of sovereign debt. There is empirical evidence that countries that do not have sound public finance, such as substantial fiscal deficit or an excessively high debt level, are likely to face higher risk premia required by financial market's participants (Schuknecht et al., 2009). Since 2009 the spread between longterm government bond yields in some euro area countries vis-à-vis the German ones experienced not only a dramatic increase, but also an augmented differentiation among countries. Recent contributions show that the determinants of the recent widening of sovereign bond premia in euro area countries are related to both general factors, such as liquidity risk, international risk aversion and contagion effects, and country-specific factors, such as fiscal positions and macroeconomic fundamentals (Attinasi et al., 2011; Gerlach et al., 2010; Arghyrou and Kontonikas, 2012; De Santis, 2012; Giordano et al., 2013). De Grauwe and Ji (2012) argue that the recent movements of government bond yield differentials cannot be explained only using economic and financial determinants. They show that the surge in the spreads of Portugal, Ireland, Greece and Spain in the period 2010-2011 was not linked to the underlying increases in the debt-to-GDP ratios, but was connected to negative market sentiments.

A factor that could play an important role in driving sovereign spread movements is political communication. Although a formal definition seems to be difficult to provide, Denton and Woodward (1990) and McNair (2011) define political communication in a broad sense, as a discussion about the allocation of public resources with a particular emphasis on the purpose and intentionality of political actors in affecting the political environment. This includes discussions that are public and, therefore, could be related to public speeches, interviews and press releases. Clearly, mass media play an important role in transmitting political communication and thus making them public knowledge (Gade et al., 2013). The provocative article "Loose lips sink the euro?" published in The Economist on the 16th of September 2011 has increased the attention on the effects of political communication in the context of the euro area sovereign debt crisis. 
The financial market effects of statements made by politicians have been the objective of many recent studies. Carmassi and Micossi (2010) analyze critical changes in the 10-year government bond spread of Portugal, Italy, Greece, Spain and France versus Germany between December 2009 and June 2010, pointing out that communications by governments fueled the financial turmoil. In particular, the messages by policy-makers were not able to convince the markets about their ability to effectively address economic imbalances. Mohl and Sondermann (2013) consider news agency reports from May 2010 to June 2011, finding that a higher level of statements' frequency from different euro area governments generated an increase in the bond spreads. In addition, they show that statements from AAA-rated countries' politicians had a significant impact on sovereign bond spreads. Goldbach and Fahrholz (2011) assess whether political events that worsened the credibility of the Stability and Growth Pact generated a shared default risk premium for euro area countries. They show that the European Commission played an important role in affecting investors' evaluations. The effects of European Central Bank (ECB) communications about unconventional measures on the Italian spread have been studied by Falagiarda and Reitz (2013). They find that the announcements of these operations were able to reduce substantially the Italian long-term government bond yield spread relative to German counterparts during the recent euro area sovereign bond crisis. Gade et al. (2013) investigate the extent to which political communication, defined as "policy-makers' pronouncements on fiscal policy and public finance", had an impact on the sovereign bond spreads in euro area countries, showing that this effect is evident in Greece, Ireland and Portugal.

This paper intends to study the effects of political announcements by Italian government's members on the Italian sovereign bond spread, i.e. the differential between the Italian 10-year government bond yield and the German one. As depicted in Figure 1, the Italian spread has experienced very high volatility between 2009 and 2013, increasing from around 140 basis points at the beginning of 2009 to more than 500 basis points at the peak of the sovereign bond crisis in 2011. It then declined to about 220 basis points at the end of 2013. As already mentioned, the volatility of sovereign risk is potentially 
connected to the ability of governments to address their duties in terms of sound public finance and debt obligations, and to provide credible long-term prospects. The recent Italian political experience motivates an intriguing comparison among the three different cabinets that followed one another during the period 2009-2013: Berlusconi's cabinet, in office until the 12th of November 2011, Monti's cabinet, in office until the 27th of April 2013, and Letta's cabinet. Therefore, it seems natural to conduct a comparative econometric analysis to assess the effectiveness of announcements by members of the three different administrations.

[Figure 1 about here]

Our definition of announcement is consistent with Gade et al. (2013) and includes policy-makers' public pronouncements on fiscal policy and public finance. In order to collect and classify announcements, we rely on the ECB Real Time Information System, which includes public news media releases from the following agencies: Bloomberg, Reuters, Dow Jones Newswires and Market News International. Overall, our dataset consists of 197 announcements by Italian government members. We examine their effects on spread movements by using GARCH models to control for time-varying volatility. The findings indicate that only fiscal policy announcements made by members of Monti's cabinet have been effective in influencing the Italian spread in the expected direction, revealing a remarkable lack of credibility for Berlusconi's and Letta's governments relative to Monti's technocratic administration. ${ }^{1}$ Moreover, we check the robustness of the results by changing the set of controls and by using both the Italian 10-year government bond yields and the Italian credit default swap (CDS) spread as dependent variables.

The remainder of the paper is structured as follows. Section 2 presents the dataset and the empirical methodology. Section 3 discusses the results, whereas robustness checks are conducted in Section 4. Section 5 concludes.

\footnotetext{
${ }^{1}$ An investigation of the factors that determined this credibility gap goes beyond the scope of this study.
} 


\section{Empirical Analysis}

\subsection{A Fiscal Policy Announcement Indicator for Italy}

Data on fiscal policy communications are obtained through the ECB Real Time Information System, which includes public news media releases from the following agencies: Bloomberg, Reuters, Dow Jones Newswires and Market News International. In particular, we collect all the announcements from Italian government members regarding fiscal policy and public finance from 2009 to 2013. Each announcement is judged in order to assess the direction of its effects on the Italian spread vis-à-vis Germany, and thus to determine the extent to which an announcement has its intended effects. Fiscal policy announcements are classified according to their content, and then coded on a numerical scale as follows:

$$
\operatorname{DomGov}_{t}= \begin{cases}+1 & \text { if the announcement is perceived to increase the spread } \\ 0 & \text { if the announcement is perceived to be neutral } \\ -1 & \text { if the announcement is perceived to reduce the spread }\end{cases}
$$

Negative (positive) values are assigned to announcements that are perceived to reduce (increase) the spread, whereas a zero is assigned to announcements that are perceived as neutral. In particular, whenever an announcement goes in the direction of additional fiscal consolidation, we classify it as spread-reducing, and vice-versa. Since this approach of classifying fiscal policy announcements is necessarily subjective, several double checks from the authors have been performed separately to avoid misclassification.

To give some examples, the following announcements are classified as potentially able to reduce the spread:

" [...] the Italian government is working on adding an article to the country's constitution requiring a balanced public budget." (Giulio Tremonti, Ministry of Finance, 4 August 2011)

" [...] there are many proposals aimed at cutting Italy's towering 1.9 trillion Euro in government debt, and our priority is to stabilize current public 
finances." (Mario Monti, Prime Minister, 29 December 2011)

“ [...] Italy's exit from the European Union's excessive deficit procedure is a priority for the country and will it give it more leeway in pushing forward growth-boosting measures." (Enrico Letta, Prime Minister, 21 May 2013)

The following announcements are instead classified as expected to increase the Italian spread:

" [...] I am not concerned about increasing Italy's already large public debt to help the rising numbers of unemployed hit by the global economic downturn." (Silvio Berlusconi, Prime Minister, 31 March 2009)

"Letta's administration suspended all key economic decisions pending a clear backing from the parties in the governing coalition. [...] There is no guarantee of government and parliamentary continuity." (Letta's office, 28 September 2013)

Overall, our fiscal policy announcement indicator includes 197 announcements from Italian government members over the period 2009-2013: 23 in 2009, 26 in 2010, 84 in 2011, 33 in 2012 and 35 in 2013. We identify 118 announcements by members of Berlusconi's cabinet (1.11 announcements per week), 57 by members of Monti's cabinet (1.05 announcements per week), 26 by members of Letta's cabinet (1.03 announcements per week). Lastly, we also collect relevant announcements related to the Italian fiscal policy and public finance stemming from domestic sources other than the government (Italian parliament, Bank of Italy, trade unions, industrial associations, etc.) and external sources (European Commission, European Council, ECB, foreign governments, International Monetary Fund, rating agencies, etc.). These statements are classified in the same way as domestic government announcements and are used as control variables in the estimation exercises. 


\subsection{Econometric Model}

In order to investigate the effect of fiscal policy announcements on the Italian spread, we need a tool capable of modeling the high time-varying volatility of the spread shown in Figure 1. Therefore, a standard Generalized Autoregressive Conditional Heteroskedastic (GARCH) model, originally proposed by Bollerslev (1986), is adopted. The conditional mean of the model is an augmented autoregressive process:

$$
\Delta S_{t}=\alpha+\beta \Delta S_{t-1}+\gamma \operatorname{DomGov}_{t}+\boldsymbol{\delta} \Delta \mathbf{X}_{\mathbf{t}}+\varepsilon_{t},
$$

where $\Delta S_{t}$ is the first difference of the spread between Italian and German 10-year government bond yields (Gerlach et al., 2010; Attinasi et al., 2011; Arghyrou and Kontonikas, 2012), DomGov is our fiscal policy indicator, calculated as explained in the previous subsection, and $\mathbf{X}_{\mathbf{t}}$ is a vector of controls. Let the error process be such that $\varepsilon_{t}=\nu_{t} \sqrt{h_{t}}$, where $\nu_{t}$ is an i.i.d. sequence with zero mean and $\sigma_{\nu}^{2}=1$. The conditional variance of $\varepsilon_{t}$ is modeled as an $\operatorname{ARMA}(1,1)$ process:

$$
h_{t}=c+a \varepsilon_{t-1}^{2}+b h_{t-1} .
$$

Consistently with previous works on the determinants of sovereign spreads, the vector of control variables $\mathbf{X}_{\mathbf{t}}$ contains: a) A volatility index for the euro area (EuroVIX $X_{t}$ ) to control for financial turmoil, as in Arghyrou and Kontonikas (2012) and Glick and Leduc (2012). We expect a positive relationship between $\Delta S_{t}$ and $\Delta$ EuroVIX $X_{t}$ b) The total stock market index for the $\mathrm{EU}\left(E U D S_{t}\right)$ to control for market-wide business climate changes in the EU, as in De Bruyckere et al. (2013). We expect a negative sign for the coefficient of $E U D S_{t}$ in the model. c) The TED spread $\left(T E D_{t}\right)$, calculated as the threemonth LIBOR rate less the US Treasury bill rate, to control for perceived credit risk in the global economy, as in Gerlach et al. (2010). The expected sign of the coefficient of this variable is positive. d) The CDS of Greece (CDSGreece $\left.)_{t}\right)$ to control for the turbulences due to the Greek sovereign crisis. We expect a positive relationship between this variable and the Italian spread. e) A dummy variable to control for ECB non-standard monetary 
policy measures, extending the list of events reported by Falagiarda and Reitz (2013). f) Weekday dummies to control for seasonality. g) Any announcement related to the Italian fiscal policy situation coming from domestic sources other than the government and external sources, such as the European Commission, the ECB, foreign governments, international institutions and rating agencies.

Parameters are estimated by (quasi-) maximum likelihood using the Broyden, Fletcher, Goldfarb and Shanno (BFGS) numerical algorithm with robust standard errors. The model is estimated using daily data, collected for the period 01:01:2009-31:12:2013. Details on the data are reported in the Appendix.

Issues of reverse causality potentially arising in Equation (2) are partially tackled by construction of the data, as in Gade et al. (2013). While the data on yield spread are collected as end-of-day, the fiscal policy indicator is constructed on the basis of announcements made during the day, with news released in the evening recorded in the next trading day and news released during weekend days reported in the following Monday. Thus, announcements on a specific day would always occur before the recording of the Italian sovereign yield spread.

\section{Results}

The goal of the paper is to check whether the effect on the Italian spread of fiscal policy announcements of the three cabinets that followed one another during the period 20092013 differs. To this purpose, the estimation is carried out over three different periods: a) 1 January 2009 - 12 November 2011 (Berlusconi's cabinet); b) 13 November 2011 - 27 April 2013 (Monti's cabinet); c) 28 April 2013 - 31 December 2013 (Letta's cabinet).

Table 1 reports the parameter estimates of the GARCH model as in equation (2) and (3). For each administration, we specify four different models by adding progressively additional control variables. Ljung-Box (LB) Q-statistics are computed to test for autocorrelation in standardized and squared standardized residuals. The $p$-values of the calculated LB-Q values show that, in most cases, the null hypothesis of no-autocorrelation up to five and ten orders cannot be rejected. Moreover, the estimated coefficients of the 
variance equation are statistically significant at conventional levels ${ }^{2}$ revealing clustering and long memory of the spread volatility. Therefore, the GARCH model is reasonably specified.

\section{[Table 1 about here]}

Turning to the estimates of the mean equation, we find that the sign of the control variables is generally as expected and their coefficients are, in most cases, statistically significant. For example, changes in the European risk measure EuroVIX $X_{t}$ are always positively and significantly (at the $1 \%$ percent level) correlated to the Italian government bond spread during Berlusconi's and Letta's administrations, whereas during Monti's administration the coefficient is significant only in the first two specifications. The results also suggest some contagion effects from the Greek government debt crisis during the years of Berlusconi's administration. There seems to be no influence from Greece during the other two periods. In contrast, an improved business climate $\left(E U D S_{t}\right)$ is associated with a significant reduction of the Italian spread, at least during the first two administrations considered. Lastly, the Italian spread reacts positively to changes in the global risk measure $T E D_{t}$ only under Letta's cabinets.

By considering our fiscal policy indicator $\left(\right.$ DomGov $\left._{t}\right)$, we observe that the coefficients during Berlusconi's administration are found not statistically significant. This is not surprising, given the deteriorated markets' confidence that forced Berlusconi to resign from office in 2011. By contrast, the announcements made by members of Monti's cabinet seem to have had a significant effect (at the 1 percent level) on the Italian spread in the expected direction in all the model specifications. The magnitude of this effect is around 5-6 basis point changes. Lastly, the coefficients of the fiscal policy indicator under Letta's period are not statistically significant. Our results clearly indicate that announcements by members of Monti's cabinet have been substantially effective in influencing the Italian spread in the expected direction, whereas announcements made under the other two governments are found to be ineffective. These findings point out a remarkable credibility gap between Berlusconi's and Letta's governments and Monti's technocratic administration.

\footnotetext{
${ }^{2}$ The estimates of the variance equation are not reported here, but are available upon request.
} 


\subsection{Split the Sample Period}

To capture potential heterogeneity over time of announcements' effectiveness under the same cabinet, we identify two sub-periods for each government. Berlusconi's cabinet is evaluated over the periods 1 January 2009 - 5 May 2010 and 6 May 2010 - 12 November 2011. The cut-off date represents the first big surge in spread volatility in the mid of 2010 observable in Figure 1. Monti's cabinet is assessed over the periods 13 November 2011 6 December 2012 and 7 December 2012 - 27 April 2013, whereas Letta's cabinet over the periods 28 April 2013 - 28 September 2013 and 29 September 2013 - 31 December 2013. In both cases, the cut-off date indicates Berlusconi's decision to withdraw the support he was giving to the government. Operationally, in Equation (2) we introduce one fiscal policy announcement indicator for each sub-period (DomGovPeriod1 and DomGovPeriod2). Table 2 reports the estimation results.

[Table 2 about here]

The response of the Italian spread to announcements made by members of Berlusconi's cabinet does not change going from the first to the second sub-period, remaining statistically not significant. Therefore, the increase in the Italian sovereign spread volatility experienced in the mid of 2010 did not alter the ineffectiveness of government's fiscal policy announcements. Interestingly, the coefficients of the second sub-period of Monti's cabinet are larger and, in the last two specifications, even more statistically significant than those relative to the first sub-period. These findings suggest that Monti's cabinet seems to have been even more credible in the absence of Berlusconi's support. Regarding Letta's government, we observe that the coefficients are not statistically significant in both periods, indicating that Berlusconi's decision to leave the majority did not generate any credibility gain for that government. These results seem to confirm the idea that a technocratic cabinet, like the Monti's one, is perceived as more credible in the eyes of market participants, at least in periods of severe sovereign debt tensions. 


\subsection{Split into Positive and Negative Announcements}

Equation (2) is then estimated distinguishing positive and negative values of our fiscal policy indicator DomGov to check whether announcements perceived as spread-reducing $\left(\right.$ DomGovPos$\left._{t}\right)$ and those perceived as spread-increasing (DomGovNeg $)_{t}$ have had a different impact on the Italian sovereign spread. The findings, shown in Table 3, indicate that for Berlusconi's and Letta's government (in the latter case only in the last two specifications) the split into positive and negative announcements does not matter, as both DomGovPos and DomGovNegt are never statistically significant. Looking at Monti's cabinet, the coefficients of both spread-reducing and spread-increasing announcements are statistically significant in all specifications and their sign is as expected. Therefore, both components contribute to the statistically significant estimates of the baseline regression shown in Table 1.

[Table 3 about here]

\section{Robustness Checks}

The results discussed in Section 3 turned out to be robust to different model specifications. To further check the robustness of the results, we estimate the model using the Italian 10-year government bond yield $\left(Y_{t}\right)$ as dependent variable in place of the spread. Six lags of the regressand are now added to remove autocorrelation of the residuals. ${ }^{3}$ The results, displayed in Tables 4-6, generally confirm what found in Section 3. More specifically, announcements by Monti's government are effective in influencing Italian long-term bond yields (Table 4) and Monti's cabinet seems to gain further credibility in the second subperiod (Table 5). However, when splitting positive and negative announcements (Table 6), spread-increasing announcements made by members of Monti's cabinet are no longer significant at conventional levels in three specifications, suggesting that spread-reducing announcements have been probably more influential in affecting yield movements. ${ }^{4}$

\footnotetext{
${ }^{3}$ For the sake of brevity, only the coefficient of the first lag is reported in Tables 4-6.

${ }^{4} \mathrm{~A}$ further robustness exercise with the Italian CDS spread as regressand has been performed. The results are broadly in line with those found for the Italian spread and the Italian long-term bond yield.
} 
[Table 4 about here]

[Table 5 about here]

[Table 6 about here]

\section{Conclusions}

The study carried out in this paper highlights the importance of political communication in influencing sovereign bond spreads. Specifically, we focus on Italian policy-makers' public pronouncements on fiscal policy and public finance, relying on news media releases from major news agencies. We perform an econometric comparative analysis between the three Italian cabinets that followed one another during the period 2009-2013, assigning a negative (positive) values to announcements that are perceived to reduce (increase) the spread, whereas a zero is assigned to announcements that are perceived as neutral. We show that during Berlusconi's and Letta's administrations fiscal policy announcements are not statistically significant. By contrast, the announcements made by members of Monti's cabinet had a significant effect on the Italian spread in the expected direction. These findings indicate a remarkable credibility gap between Monti's technocratic administration and Berlusconi's and Letta's governments.

They are not reported here, but are available upon request from the authors. 


\section{References}

Arghyrou, M. G. and Kontonikas, A. (2012). The EMU sovereign-debt crisis: Fundamentals, expectations and contagion. Journal of International Financial Markets, Institutions and Money, 22(4):658-677.

Attinasi, M., Checherita, C., and Nickel, C. (2011). What explains the surge in euro area sovereign spreads during the financial crisis of 2007-2009? In Kolb, R. W., editor, Sovereign Debt: From Safety to Default, pages 407-414. John Wiley \& Sons, Inc.

Bollerslev, T. (1986). Generalized autoregressive conditional heteroskedasticity. Journal of Econometrics, 31(3):307-327.

Carmassi, J. and Micossi, S. (2010). The role of politicians in inciting financial markets to attack the eurozone. EuropEos, CEPS, Brussels 4.

De Bruyckere, V., Gerhardt, M., Schepens, G., and Vander Vennet, R. (2013). Bank/sovereign risk spillovers in the European debt crisis. Journal of Banking and Finance, 37(12):4793-4809.

De Grauwe, P. and Ji, Y. (2012). Mispricing of sovereign risk and multiple equilibria in the Eurozone. LICOS Discussion Papers 30412, LICOS - Centre for Institutions and Economic Performance, Leuven.

De Santis, R. A. (2012). The Euro area sovereign debt crisis: Safe haven, credit rating agencies and the spread of the fever from Greece, Ireland and Portugal. Working Paper Series 1419, European Central Bank.

Denton, R. E. and Woodward, G. C. (1990). Political communication in America. Praeger, New York.

Falagiarda, M. and Reitz, S. (2013). Announcements of ECB unconventional programs: Implications for the sovereign risk of Italy. Kiel Working Papers 1866, Kiel Institute for the World Economy. 
Gade, T., Salines, M., Glöckler, G., and Strodthoff, S. (2013). Loose lips sinking markets?": The impact of political communication on sovereign bond spreads. Occasional Paper Series 150, European Central Bank.

Gerlach, S., Schulz, A., and Wolff, G. B. (2010). Banking and sovereign risk in the Euro area. CEPR Discussion Papers 7833.

Giordano, R., Pericoli, M., and Tommasino, P. (2013). Pure or wake-up-call contagion? Another look at the EMU sovereign debt crisis. International Finance, 16(2):131-160.

Glick, R. and Leduc, S. (2012). Central bank announcements of asset purchases and the impact on global financial and commodity markets. Journal of International Money and Finance, 31(8):2078-2101.

Goldbach, R. and Fahrholz, C. (2011). The euro area's common default risk: Evidence on the Commission's impact on European fiscal affairs. European Union Politics, 12(4):507-528.

McNair, B. (2011). An introduction to political communication. Taylor \& Francis.

Mohl, P. and Sondermann, D. (2013). Has political communication during the crisis impacted sovereign bond spreads in the euro area? Applied Economics Letters, 20(1):4861.

Schuknecht, L., Von Hagen, J., and Wolswijk, G. (2009). Government risk premiums in the bond market: EMU and Canada. European Journal of Political Economy, 25(3):371384. 


\section{Figures and Tables}

Figure 1: Evolution of the Italian spread vis-à-vis Germany (2009-2013)

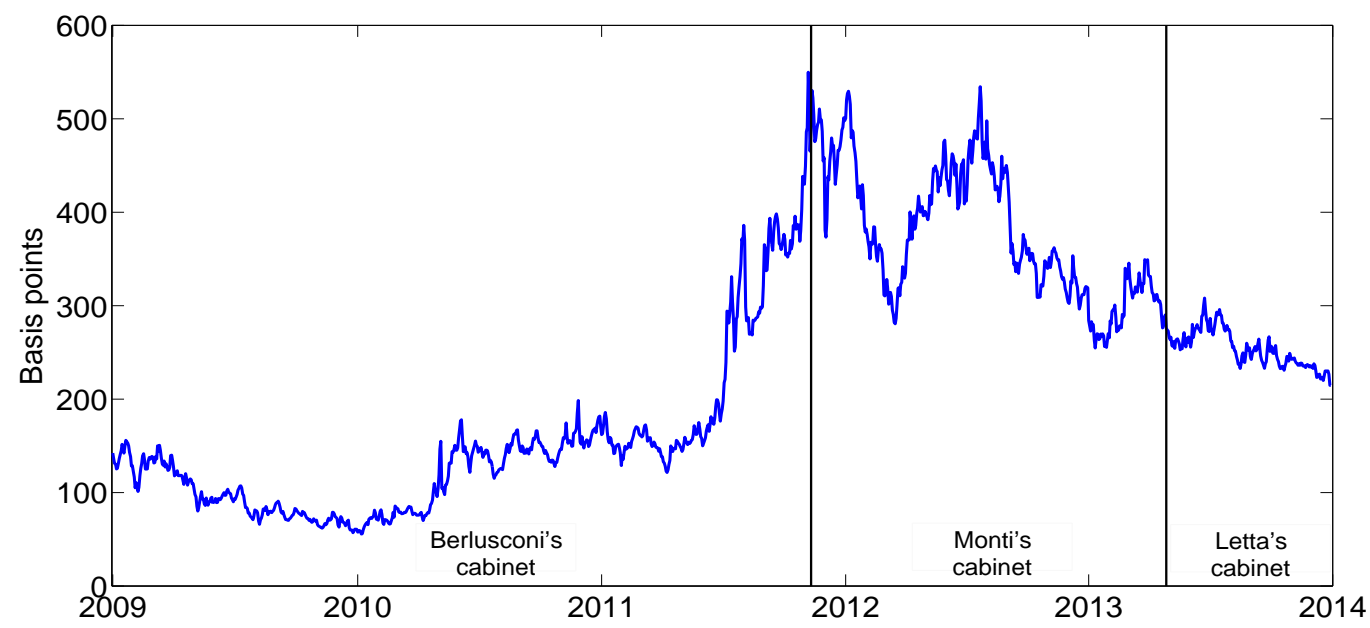

Source: Data from Thomson Reuters-Datastream. 


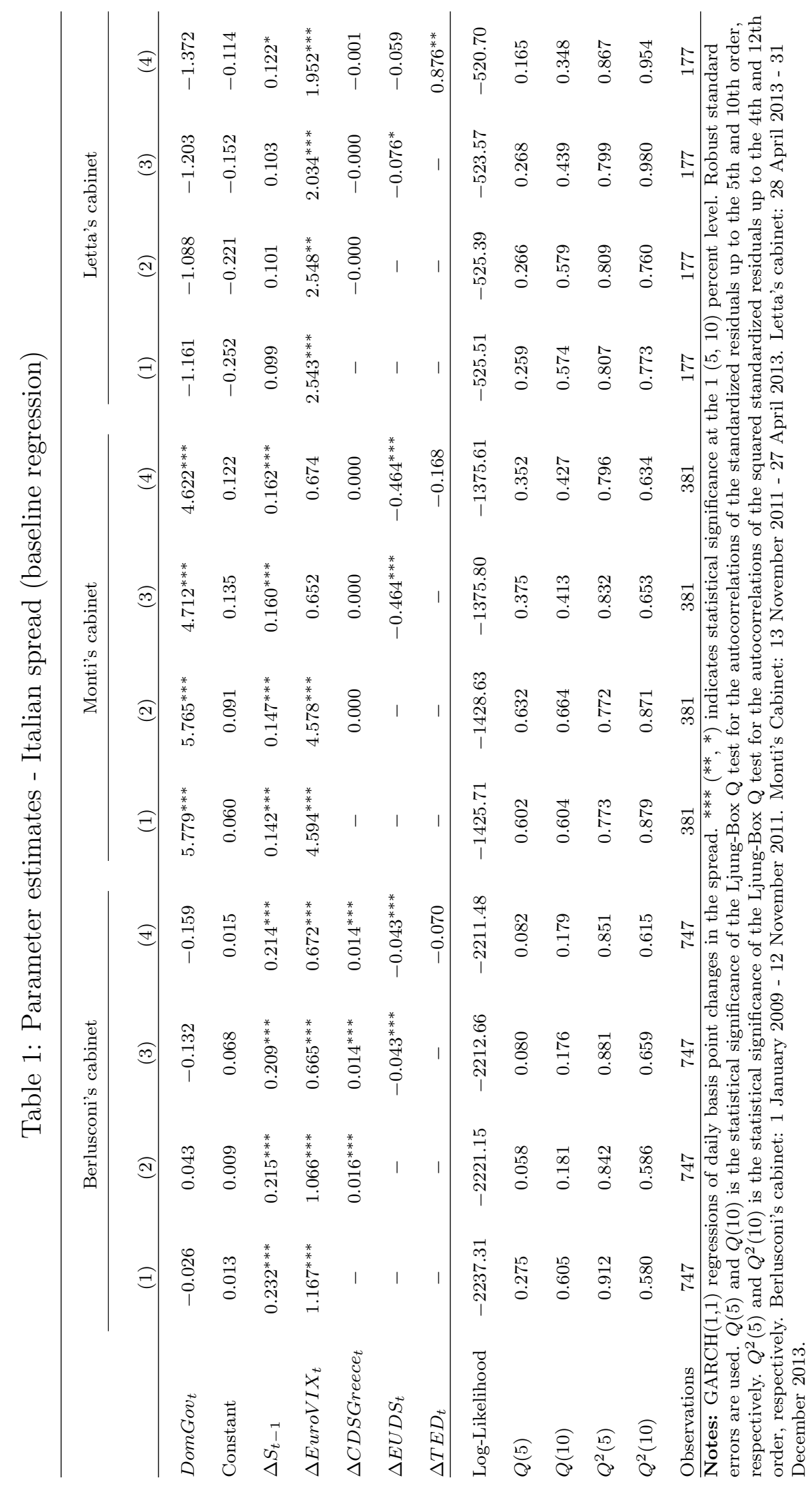




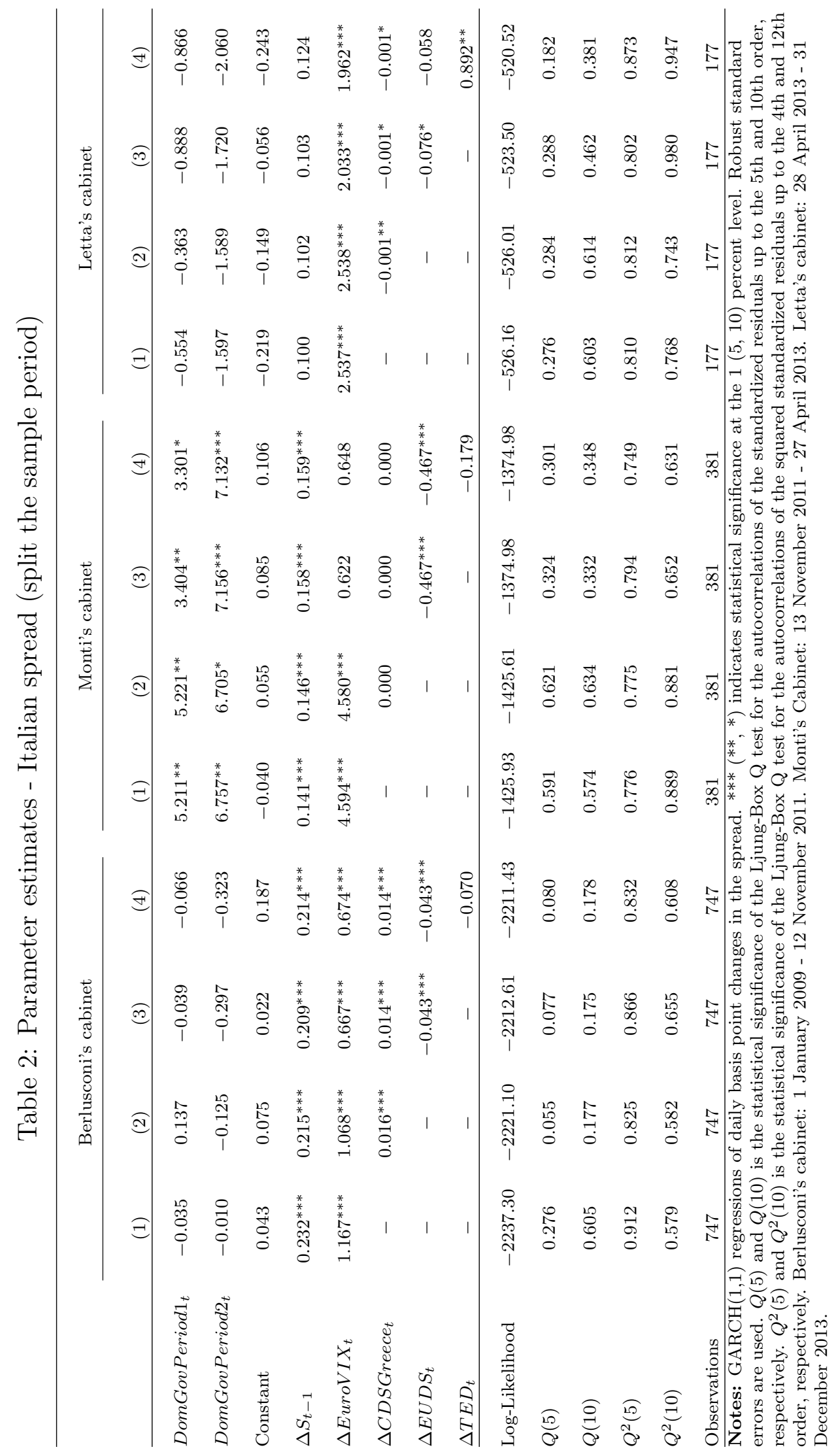




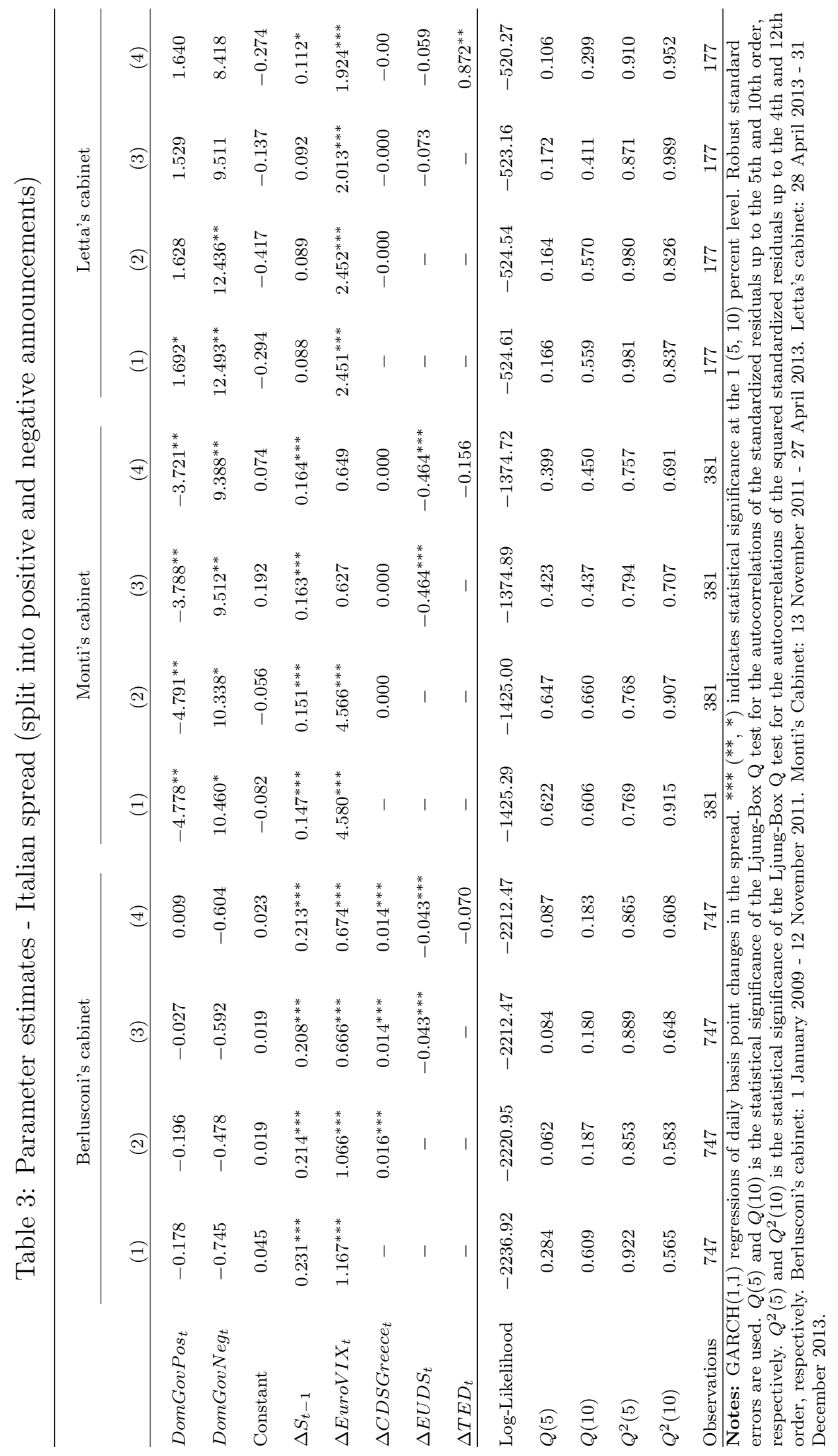




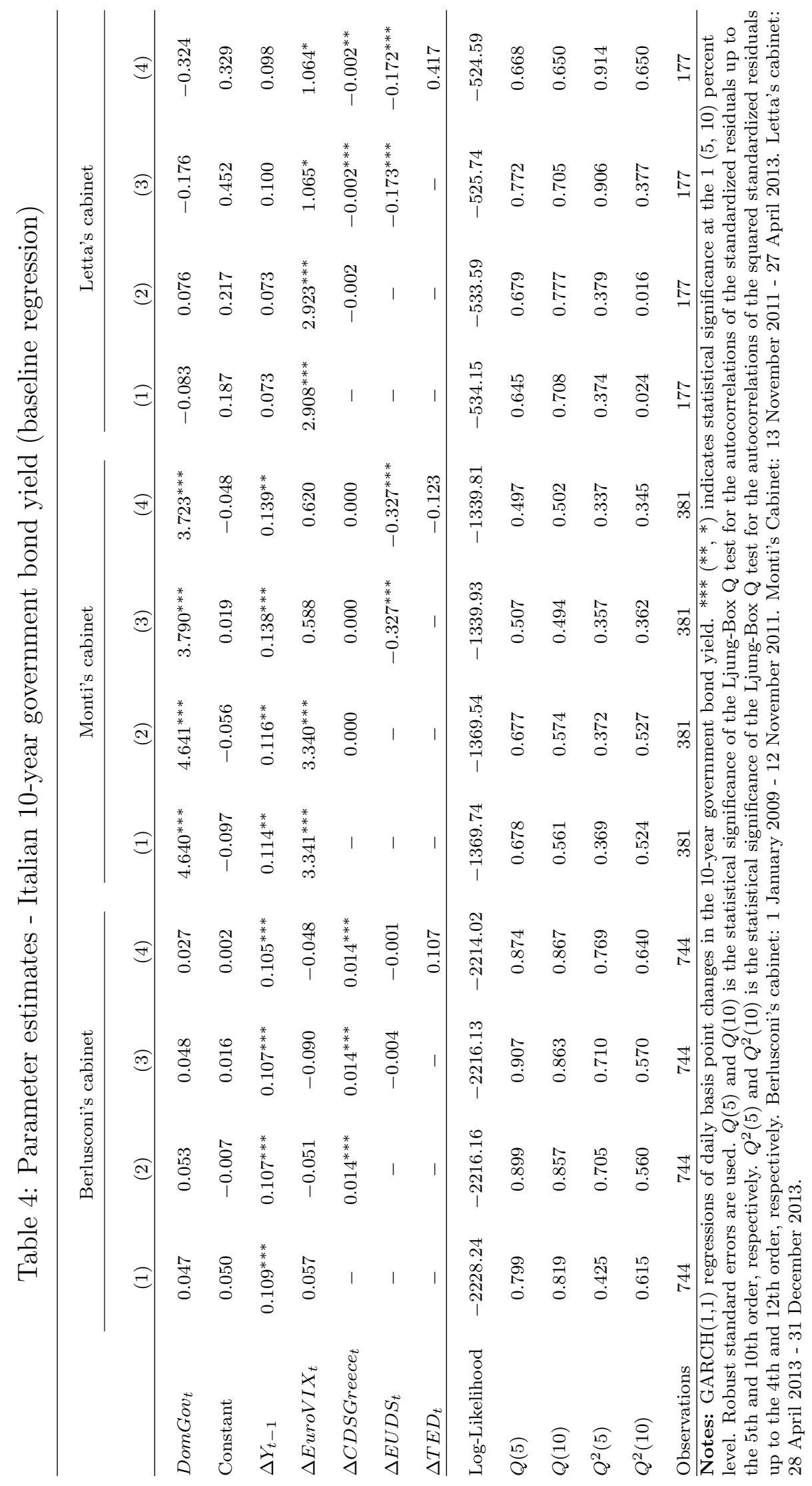




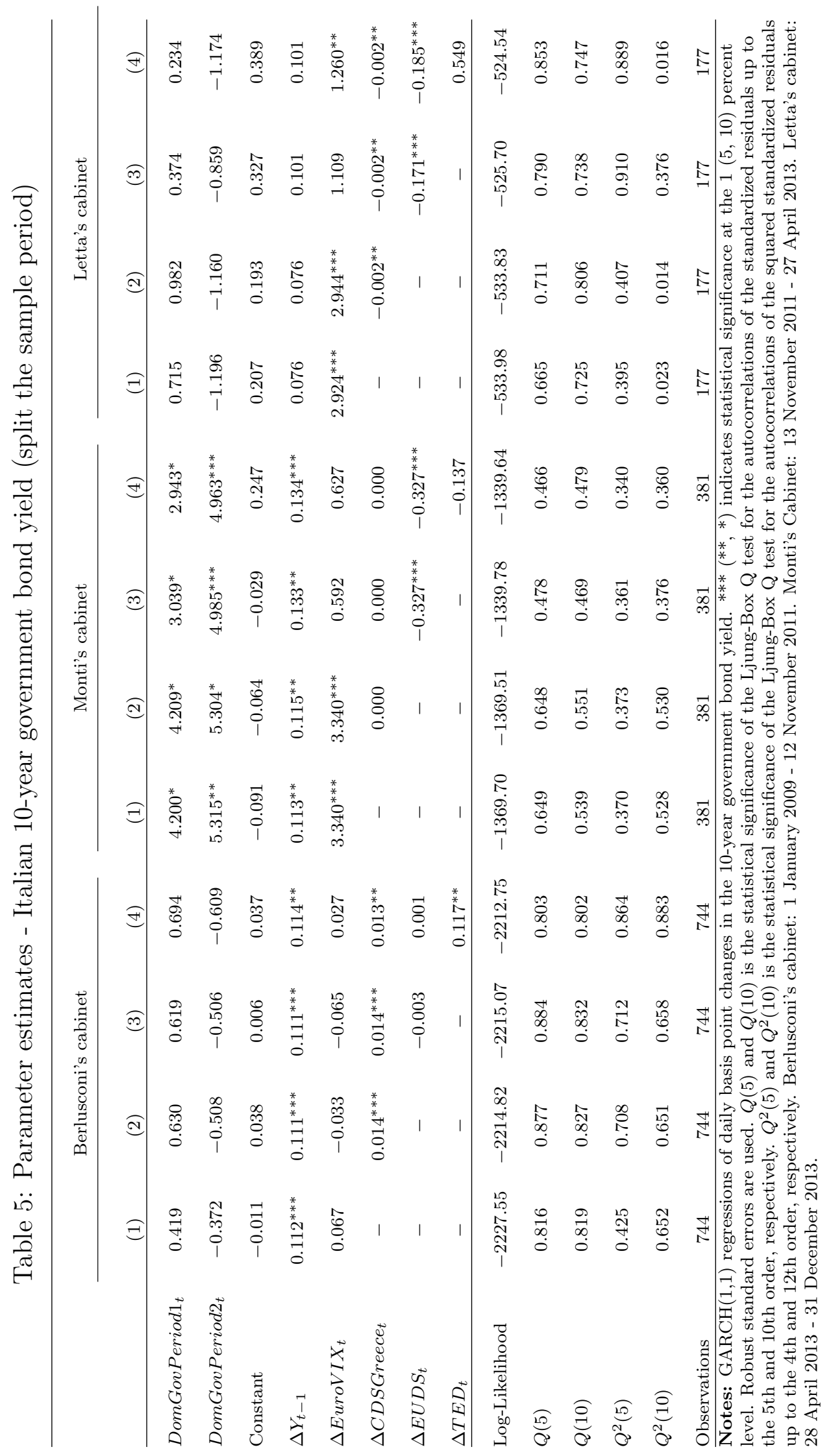




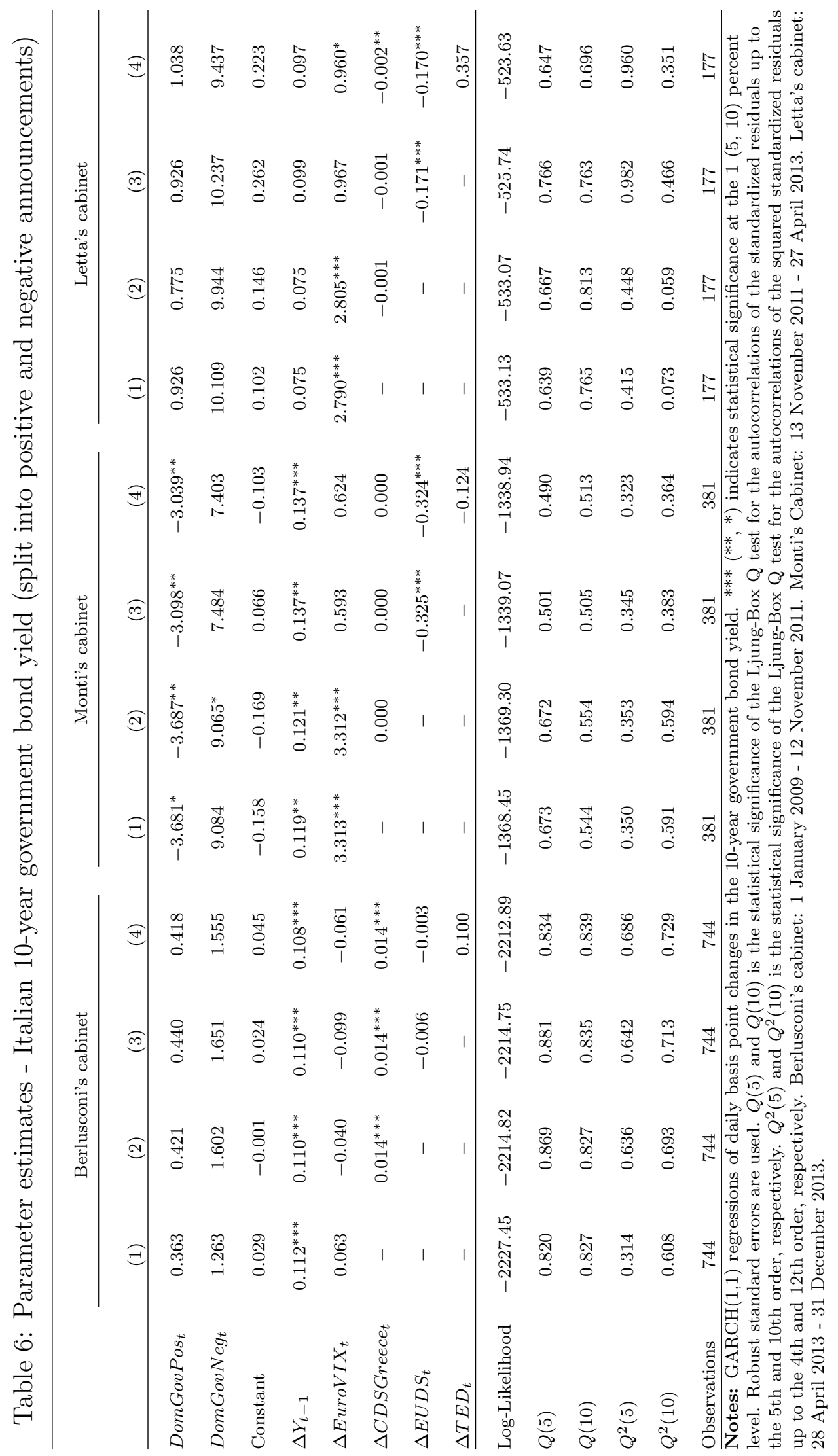




\section{Appendix: The Data}

Data on fiscal policy communications are obtained through the ECB Real Time Information System, which includes news media releases from the following agencies: Bloomberg, Reuters, Dow Jones Newswires and Market News International.

Financial daily data are obtained from the Thomson Reuters-Datastream database:

- Long-term bond yield for Italy: Italy Benchmark Bond 10 YR - Redemption Yield (Datastream mnemonic: ITBRYLD)

- Long-term bond yield for Germany: Germany Benchmark Bond 10 YR - Redemption Yield (Datastream mnemonic: BDBRYLD)

- EuroVIX: VSTOXX volatility index (Datastream mnemonic: VSTOXXI)

- CDS Greece: Greece Senior 10 Year Credit Default Swap (Datastream mnemonic: GRGVTSX)

- Total stock market index for the EU: EU-DS Market (Datastream mnemonic: TOTMKEU)

- TED spread: TED spread rate - middle rate (Datastream mnemonic: TRTEDSP)

Data on ECB non-standard monetary policy events are collected using the dataset in Falagiarda and Reitz (2013), which has been extended to include measures announced in 2013. 


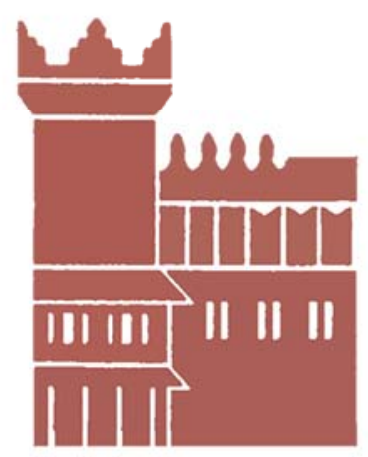

Alma Mater Studiorum - Università di Bologna DEPARTMENT OF ECONOMICS

Strada Maggiore 45

40125 Bologna - Italy

Tel. +39051 2092604

Fax +390512092664

http://www.dse.unibo.it 